\title{
9 Case Matching and Conflicting Bindings Interference
}

\author{
Pavel Logačev and Shravan Vasishth
}

University of Potsdam

\begin{abstract}
Similarity-based interference (SBI) has recently gained more attention in the domain of sentence processing (e.g. Gordon et al., 2007). In this paper we demonstrate that similarity can also have facilitative effects on processing, a finding that interference theories such as Gordon et al's cannot explain. We offer an explanation for such interference effects as well as the facilitative effects in terms of independently motivated assumptions about the structure of memory representations (Hommel, 1998; inter alia). An attractive aspect of this explanation of similarity-based interference and facilitation effects is that so-called case-matching phenomena can also be accounted for. To this end we present two experiments: In Experiment 1 we demonstrate that case matching can occur even with noncoreferent NPs, given a sufficient level of similarity. In Experiment 2 we show that case matching is really driven by abstract case proper as opposed to other properties canonically associated with it. In sum, we provide a unified explanation for interference, facilitation and case-matching effects. A broader implication of this account is that case ambiguities are not resolved immediately but rather the multiple representations are maintained in parallel---a mechanism that is clearly not compatible with serial parsing strategies.
\end{abstract}

Acknowledgments We would like to thank Gisbert Fanselow for very helpful suggestions concerning the design of Experiments 1 and 2, as well as Felix Engelmann, Esther Sommerfeld, and Titus von der Malsburg for extensive discussions of the ideas presented in this paper. Furthermore we thank Monique Lamers for very helpful comments on the first draft of this paper.

\subsection{Introduction}

The process of comprehending a sentence, just like any other cognitive process, requires us to use our memory. As we incrementally parse a sentence, linguistic objects have to be stored in working memory (WM) for later usage. Storage and 
recall, however, are usually not perfect - they are subject to a number of limitations imposed by principles of WM as well as the structure of objects encoded therein (e.g. Anderson and Paulson, 1978; Lewis, 1996; Miller and Chomsky, 1963; Oberauer and Kliegl, 2006). However, the observable effects of these limitations, can help reveal the internal structure of the representations used in parsing. One well-attested constraint on memory is similarity-based interference (SBI), that is increased difficulty in distinguishing between two objects in WM due to their similarity. One of the adverse effects of SBI is worse performance in understanding sentences containing similar noun phrases (NPs) as compared to dissimilar ones. In this paper, similarity will be operationalized as a match along some dimension, such as definiteness, animacy, etc., which may or may not be linguistic in nature. Since it is not restricted to the linguistic domain (e.g. Anderson and Paulson, 1978) we assume that SBI is a general principle of memory, rather than something specific to language.

In this paper we will propose the idea that a specific storage and retrieval mechanism in memory is responsible for SBI (and importantly, the opposite of SBI in some cases). We will argue that the content-addressability of human WM requires objects in WM to represented as a set of bindings between this objects' features - and that this architecture of memory gives rise to a phenomenon known as case matching (or case attraction). In Experiments 1a-c we will provide experimental evidence favoring this account over the explanations proposed so far (e.g. Bader and Meng, 1999; Fanselow et al., 1999; Schlesewsky, 1996). Based on the results of Experiment 2, we will argue that case matching is in fact driven by abstract case and not by factors that case may be confounded with. We will furthermore explore the implications of this analysis for the representation of morphological case ambiguities and argue that ambiguous NPs must be represented by several distinct objects in WM.

Our work is set within the cue-based parsing framework (Lewis, 1996;

Lewis and Vasishth, 2005; Lewis, Vasishth and Van Dyke, 2006; Van Dyke and Lewis, 2003; Vasishth, Brüssow, Lewis and Drenhaus, 2008; Vasishth and Lewis, 2006; Vasishth, 2008), which puts particular emphasis on the notion of retrieval. During the parsing process, every head (e.g. a verb) has to be integrated with its dependents (e.g. subject and/or object). This leads to the interesting situation that in head-final constructions the dependent has to first be retrieved from memory before integration can take place; this scenario is interesting because if multiple potential candidates for integration are present in memory, a choice has to be made during the retrieval process. The role of interference can only be investigated when several alternative candidates for retrieval exist. In the cue-based parsing framework, every object stored as a chunk (i.e. an object in WM). The probability and latency of retrieval of a dependent will depend on, among other factors, its activation. Activation in turn, depends on the number of times the object has been retrieved in the past and the amount of time that has passed since (time-based decay).

Since the model assumes a content-addressable memory (e.g. McElree 2000), retrieval is mediated by certain cues, which identify the linguistic object to 
be retrieved. These cues are derived from our syntactic, semantic or world knowledge, such as number (if the verb bears number agreement), case of the dependent, animacy, - and other factors determining the grammaticality or even typicality of usage of a dependent with the current head. The match between these cues and the target item is another significant determinant of the probability and latency of a successful retrieval operation.

In the following section we will present an overview of well-established phenomena involving retrieval interference, and the theoretical proposals in the literature that address the empirical evidence for retrieval interference.

\subsection{Similarity-based Interference}

Similarity-based interference - interference due to a match of objects along some dimension - plays an important role in sentence comprehension. When readers encounter words or phrases similar to preceding ones, they often have difficulty in processing them. Gordon et al. (2001) demonstrated that subject- and object-clefts like (1a) and (1b) respectively are processed faster when the noun phrases (NPs) are of different types. Sentences with two proper names as well as those with two definite NPs were processed slower than mixed conditions. Comprehension accuracy was also lower for the similar conditions compared to the dissimilar ones. Both effects were more pronounced in object clefts.

(a) It was the barber/John that saw the lawyer/Bill in the parking lot.

(b) It was the barber/John that the lawyer/Bill saw in the parking lot.

In subsequent work, Gordon et al. (2002) asked participants to memorize a list of three common nouns or three proper names before reading sentences as in (1). Both the NPs in the sentence were either definite descriptions or proper names. Reading times as well as error rates on recall of the memorized list were significantly higher in the matched conditions, suggesting that interference effects can be caused by an external memory load - and therefore arise as a consequence of general memory constraints. Similar effects can be found for animacy (Suckow, Vasishth \& Lewis, 2005) and case marking. Regarding case marking, Babyonyshev and Gibson (1999) collected complexity ratings for double-embedded Japanese sentences in which two of the grammatical subjects were always marked with the nominative case marker $-g a$ while a third one was either marked with $-g a$ or with the topic marker - wa. Although both options are grammatical in Japanese, participants found the sentences with two nominative markers and one topic marker easier to understand than sentences with three nominative markers. Babyonyshev and Gibson interpreted this result as evidence for lower structural prediction cost (because more verb-phrases are predicted for three nominative NPs than for two nominative- and one topic-marked NP). However, the results can also be inter- 
preted as evidence for lower interference cost: the three nominative-marked NPs could cause more interference than two nominative- and one topic-marked NP.

Assuming such an interpretation of the Babyonyshev and Gibson results, it is not clear whether interference is due to phonological or more abstract properties of the case markers. Fedorenko, Babyonyshev and Gibson (2004) addressed this issue by making use of different inflection paradigms for feminine and masculine nouns in Russian. In a self-paced reading experiment, they investigated how case marking and abstract case (i.e. case without explicit morphological marking) affect retrieval interference. ${ }^{1}$

Fedorenko et al. (2004) varied case markers and abstract case independently from each other. While in both, $(2 \mathrm{a})$ and $(2 \mathrm{c})$, the violinist and the pianist bear the same morphological case marker $-u$, their abstract case matches only in (2a) (both NPs are accusative), because in (2a) the verbs respect and anger both assign accusative case to their objects. In (2c), however, the verb call in (2c) assigns dative case and thus abstract case does not match. In (2b) and (2d) the morphological marking of the two NPs differs, but it is only in (2d) that the abstract case differs as well. The authors found significantly higher reading times at the verb angered in condition (2a), but no significant differences between the other conditions. They conclude that case interference does not stem from identical morphological case marking or matching abstract case alone. Rather, both need to match for case interference to arise. ${ }^{2}$

(2)

$$
\begin{array}{llll}
\text { [[Uvažavšuju } & \text { skripačku] } & \text { pianistku }] & \text { razozlil } \\
\text { respecting } & \text { violinist FEM.ACC } & \text { pianist.FEM.ACC } & \text { angered }
\end{array}
$$

'angered the pianist, who respected the violinist'

$\begin{array}{llll}\text { [[Uvažavšuju } & \text { skripača }] & \text { pianistku }] & \text { razozlil } \\ \text { respecting } & \text { violinist.MASC.ACC } & \text { pianist.FEM.ACC } & \text { angered }\end{array}$

'angered the pianist, who respected the violinist'

(c) [[Pozvonivšuju skripaču $]$ pianistku $]$ razozlil
having.called violinist.MASC.DAT pianist.FEM.ACC
angered

(d) [[Pozvonivšuju skripačke] pianistku] razozlil

having.called violinist.FEM.DAT pianist.FEM.ACC angered 'angered the pianist, who had called the violinist'

$\begin{array}{lllll}\text {... } & \text { dirižer } & \text { iz } & \text { izvestnoj } & \text { konservatorii } \\ \text { conductor.NOM } & \text { from } & \text { famous } & \text { conservatory }\end{array}$

\footnotetext{
${ }^{1}$ Retrieval interference occurs during a retrieval operation, e.g. while processing the head, but it is dependent on the relation between the target item and competitors.

2 There is one caveat to this experiment, however. In (2a) and (2d) the nouns involved match in gender, which is not so in (2b) and (2d). So the data do not exclude an interpretation in which gender and abstract case conspire to cause interference if both match, while the case marker does not have any effect at all.
} 
- posle generalnoj repetitsii.

'After the final rehearsal, the conductor from a famous conservatory angered the pianist, who respected/had called the violinist.'

Other evidence suggests that interference arises due to retrieval cues that drive integration processes. In a self-paced reading study, Van Dyke and McElree (2006) presented object clefts like (3) with and without a preceding memory load (Load and No-Load). In the Load conditions, participants had to memorize a list of three proper nouns before reading the sentence. Critically, all nouns were potential objects of fixed in (3b), but not of sailed in (3a). In the Load conditions they found a significant slowdown in (3b) as compared to (3a), but not in the No-Load conditions. Consistent with the idea of retrieval interference, the slowdown occurred at the verbs fixed and sailed respectively.

(a) It was the boat that the guy who lived by the sea sailed in two sunny days.

(b) It was the boat that the guy who lived by the sea fixed in two sunny days.

On these grounds Van Dyke and McElree argue that similarity-based interference (SBI) arises as a consequence of cue-based retrieval operations needed for retrieving dependent NPs from WM in order to combine them with the verb. When the clefted object is retrieved at the verb fixed or sailed in (3), one of the cues will be its 'fixabiliy' or 'sailability'. They claim that the better the cues match the object boat in memory, the higher its probability of being retrieved. But in addition, the better the cues match the competitors from the memory list, the higher their retrieval probability. Higher retrieval probability for the competitors means lower retrieval probability for the target. Thus, the stronger the competitors for boat, the less likely it is to be retrieved. Since the items in the memory list are more plausible objects for fixed than for sailed, they share more of the targets features required by the retrieval cues in (3b). Thus, cue-overload makes them stronger competitors for boat in (3b) than in (3a) - and the probability of retrieving a wrong item is higher for fixed. Hence the slowdown in (3b) given a memory load.

How can the Van Dyke and McElree interference model explain the Gordon et al and Fedorenko et al results? It seems that it cannot. Consider Gordon and colleagues' findings again. The influence of NP type in (1) (repeated in (4)) cannot be mediated by a cue-overload: verbs do not in general subcategorize for the type of referential expression of their arguments. But even if they did in this case - a match in referential properties of two NPs seems to be impossible to subcategorize for, because a match does not help in identifying a single object, it is rather a relation between two objects. Therefore, it appears that the Van Dyke and McElree model cannot explain why Gordon and colleagues find interference effects due 
to the referential types of NPs.

(4)

(a) It was the barber/John that saw the lawyer/Bill in the parking lot.

(b) It was the barber/John that the lawyer/Bill saw in the parking lot.

The Van Dyke and McElree model cannot explain Fedorenko and colleagues' findings either: while abstract case in (2) is a very probable candidate for a retrieval cue, the surface form of the case marking seems an unlikely one. Since the effect in (3) does not appear to be reducible to a non-cue-based mechanism, it follows that we are dealing with two distinct kinds of interference.

Moreover, in contrast to Van Dyke and McElree's claims concerning cuebased SBI, recent work (Logacev and Vasishth, in preparation) has demonstrated that non-cue-driven SBI does not rise monotonically with increasing similarity. In an eye tracking study, we presented stimuli such as (5), consisting of a matrix clause with an intervening relative clause. We manipulated both subjects (i.e. painter and sculptor in (5a)) along two different dimensions: gender and noun type. Gender is overtly marked in German and it could be masculine (Maler) or feminine (Malerin) in this experiment. For noun type we chose occupations such as painter, sculptor, policeman, etc. and nationalities. We were interested in the effect of match and mismatch along one or both these dimensions. In (5) this manipulation is illustrated for the first subject noun phrase. In (5b) both subjects match only in noun type, in (5c) only in gender, in (5a) in both, and in (5d) in none of these features. Importantly, noun type and gender match are variables that cannot be subcategorized for, and therefore any interference effect during retrieval must be non-cue-driven.

(5)

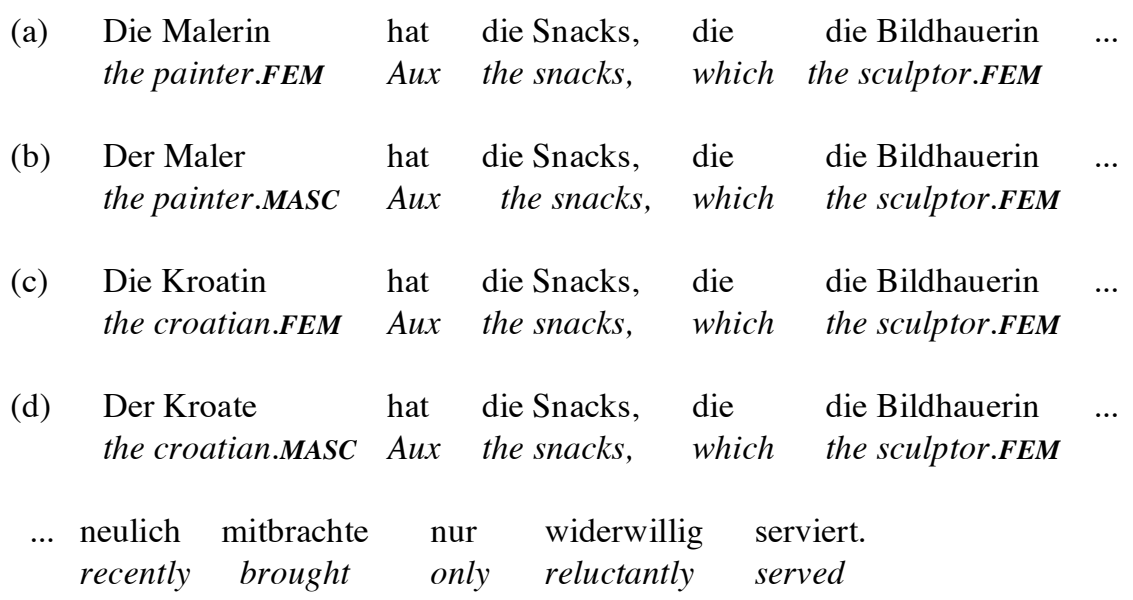


'The painter/Croatian only reluctantly served the snacks that the sculptor bought recently.'

Conditions with one matching feature, i.e. $(5 b, c)$, were read more slowly at the embedded verb mitbrachte than the maximally mismatching condition (5d) and the maximally matching (5a). This means that a match in gender has an adverse effect on processing, but only if the noun type does not match. If the noun type does match, a gender match facilitates processing, contrary to the predictions of all current SBI theories. In other words, a noun type match facilitates a gender match, and a noun type mismatch facilitates a gender mismatch during retrieval.

This surprising finding is not limited to language processing. Hommel (1998) showed participants two visual objects (S1 and S2) on a computer screen with a $500 \mathrm{~ms}$ interval in-between. These were varied in shape and color. For instance, there could be a red ' $O$ ' and a green ' $\mathrm{X}$ '. Both objects were varied with respect to color, shape and location on the screen. After the second stimulus (S2) was presented, participants had to respond to its shape by pressing a corresponding button (e.g. right for ' $\mathrm{X}$ ', left for ' $\mathrm{O}$ '). Interestingly, the reaction time for this decision was affected by the relationship between the two objects. Reaction time was slower if the shape (respectively color) of S1 was identical in S2, while the colors (respectively shapes) of S1 and S2 were different; but if both shape and color were identical, reaction time was faster. The same type of interaction was present between shape and location repetition as well. (This effect appears to be very reliable, see also Hommel \& Colzato 2004; Colzato, Raffonne \& Hommel 2006).

Hommel explains these effects by assuming a particular structure of socalled object files, which are are created for every perceived object. To form such an object file, features such as shape, color and location are linked to each other by pairwise bindings. When an object is processed it is encoded in memory and its shape will be bound to its color and also to its location, thereby forming an object file, i.e. the object's representation.

We will define a binding $B_{1}$ as conflicting with another binding $B_{2}$ if one feature is common to both bindings, and $B_{1}$ links this feature to another feature $F_{1}$, while $\mathrm{B}_{2}$ links it to $\mathrm{F}_{2}$, and $\mathrm{F}_{1}$ and $\mathrm{F}_{2}$ are distinct. ${ }^{3}$ Hommel assumes that conflicting bindings are the source of interference effects. For example, if only one feature of stimulus object $\mathrm{S} 1$ is present in $\mathrm{S} 2$, conflicting bindings will incur higher processing costs. While for a green object ' $\mathrm{X}$ ', the color feature green will be bound to the shape feature $X$, the same color feature would have to be bound to another shape feature for a green ' $O$ '. These bindings would conflict, and therefore interfere. They would not interfere if the two objects presented were a green ' $O$ ' and a red ' $\mathrm{X}$ '. In this case the objects would not share any (experimentally relevant) fea-

${ }^{3}$ We will furthermore assume throughout this paper, that $B_{1}$ and $B_{2}$ will conflict only if $F_{1}$ and $F_{2}$ are of the same type, e.g. case, gender, etc. This is only for expository reasons. Untyped bindings make the same predictions. 
tures, and thus no feature would be involved in two conflicting bindings. This sort of encoding seems not to be domain-specific (e.g. Hommel, 1998).

Our explanation for the surprising interaction in (5) runs along the same lines. We assume that linguistic objects consist of features linked to each other by pairwise bindings, just like in object files. Every object is represented by the totality of its bindings, i.e. links between its features. The source of interference in retrieval are not just the features shared by other objects, it is rather the conflicting bindings which are part of those objects.

Let us revisit the findings in (5) in light of this architecture. Figure 9.1 a schematically depicts the bindings involved in representing the NPs in (5a). We focus only on features related to noun type and gender. The representation of [the sculptor $\left._{F E M}\right]$, marked as NP1 in the figure, involves bindings between the feature bundle associated with occupations and the feature (or feature bundle) associated with feminine gender. [the painter ${ }_{F E M}$ ], marked as NP2, involves the very same bindings. Since they are identical, there is no conflict present. In Figure 9.1b, on the other hand, [the painter ${ }_{\text {MASC }}$ ] has a binding between occupation and masculine gender. Since both sets of bindings involve occupation, but link it to different genders, they are conflicting in (5b). This conflict leads to processing difficulty. The explanation for the reverse effect in $(5 \mathrm{c}, \mathrm{d})$, i.e. facilitated processing of a gender mismatch if the noun type is different, is that in (5c) [Figure 9.1c] the same gender is bound to nationality and occupations, while in (5d) [Figure 9.1d] each noun type is associated with a different gender, so there is no conflict in (5d).

Insert Figure 9.1 a about here.
Insert Figure 9.1b about here.
Insert Figure 9.1c about here.
Insert Figure 9.1d about here.

Overall, there seems to be evidence for two mechanisms known under the name SBI, cue-based (Van Dyke and colleagues) and non-cue-based (Gordon and colleagues and Fedorenko and colleagues). Since the latter stems from conflicting bindings interfering during retrieval and exhibits a slightly different pattern than SBI in the sense of Van Dyke and McElree (2006), conflicting bindings retrieval interference (CBRI) might be a more appropriate term for non-cue-based interference. This kind of interference probably reflects difficulty in activating (i.e. retrieving) an item in content-addressable memory.

But how can CBRI account for Gordon et al.'s and Fedorenko et al.'s results? Let us assume, for the sake of simplicity, that the strength of interference depends on the sum of conflicting bindings involved in the representation of the target item and its competitor and that both objects have the same number of features. Most of the time, when an object is retrieved there will be some conflicting bindings. The observed slowdown in processing is due to a relative difference in the number of such bindings between two conditions. If in one condition there are more conflicting bindings than in another, an interference effect arises. Since all features are linked to each other by pair-wise bindings, the feature bundle manipu- 
lated in the experiment will be linked to all other features in the object. Thus, if both objects match in this feature, all its links to other matching features will be non-conflicting, while all its links to mismatching features will conflict. If it mismatches, the opposite is true: each link to a matching feature will be a conflicting one, whereas each link to a mismatching feature will be non-conflicting. ${ }^{4}$

The amount of additional interference caused by an additional matching feature will depend on the difference between mismatching and matching features excluding the ones subject to the experimental manipulation, i.e. the amount of dissimilarity not affected by the experimental manipulation. If there are more mismatching features than matching ones, an increase in similarity will turn more non-conflicting bindings into conflicting ones than vice versa. The net effect will be an increase in the number of conflicts, yielding interference. If, however, there are more matching features than mismatching ones, interference will decrease.

Roughly speaking, interference occurs whenever the similarity of two dissimilar objects is increased. ${ }^{5}$

The critical manipulation in the Gordon et al. experiment in (1) was the noun phase type. It is not implausible to assume that the similarity of the noun phrases used, excluding features affected by the experimental manipulation, is not very high, given that the nouns were not necessarily related and referred to completely distinct discourse referents. Additionally, the effect was most pronounced in objects clefts, in which one NP was a subject and the other one was the object.

As for the Fedorenko et al. experiment (example (2)), the manipulation was somewhat more complex. Three features of the noun phrase were manipulated: the case marker, the abstract case, and the gender of the first noun phrase. Although the last feature was not an experimental factor, it had to be changed to switch the inflectional class and thus dissociate case marking from abstract case. The only condition suffering interference was (2a) in which the target and the competitor shared all three of them. Again, the two nouns had distinct discourse referents, and while the first one was the patient or theme of the participle (first verb), the second one was its agent.

\footnotetext{
${ }^{4}$ More formally, if two objects have $n$ and all features belonging to an object are bound to each other every feature will be bound to $(n-1)$ others. Since bindings are bidirectional, both objects will consist of $((n-1)+\quad(n-2)+\ldots+2+1)$ bindings each. If they match in $k$ features, each object will contain $k *(n-k)$ conflicts, because only bindings from matching to mismatching features are conflicting, and every object contains $k$ of the former and $(n-k)$ of the latter. If we increase similarity by making $q$ more features match, the number of conflicts will be $(k+q) *(n-(k+q))$. An interference effect due to additional similarity corresponds to $k *(n-k)<(k+q) *(n-(k+q))$. One can easily show that this is the case iff $\mathrm{k}<\mathrm{n} / 2$. Thus one can formally demonstrate that for low levels of similarity, CBRI predicts an interference effect if the objects are made more similar, while for high levels of similarity it predicts the opposite.

${ }^{5}$ Admittedly, the exact differences between the numbers of matching and mismatching features for any two objects may appear to be a free parameter in the CBRI theory. They are, however, not completely unconstrained. Although precise quantitative predictions of CBRI rely on the objects' similarity at least on an interval scale, we can still derive qualitative predictions from similarity rankings on an ordinal scale, available from uncontroversial intuitions and possibly similarity rating studies.
} 
Under the assumption that in both experiments the number of mismatching noun phrase features outweighed the number of matching ones, CBRI predicts an interference effect, thereby accounting for non-cue-based interference.

Critically, however, if the noun phrases involved exceed a certain level of similarity, we should observe the reverse effect. An increase in similarity should not slow down, but rather speed up processing. It is this property of CBRI, which makes it able to account for a phenomenon called case matching, which we discuss in the next section.

\subsection{Case matching}

Case attraction, first discussed by Bader (1994), also known as case matching can be roughly characterized as the facilitation of sentences in which two coreferent NPs bear the same case. It was demonstrated in self-paced reading (Schlesewsky, 1996; Fanselow et al., 1999) and speeded acceptability judgment tasks (e.g. Bader and Meng, 1999).

For example, the noun Opernsängerinnen in (6) is locally ambiguous with respect to case. Morphologically, it can be nominative, accusative or dative, but the presence of the nominative NP der Tenor excludes the nominative reading. Opernsängerinnen is disambiguated by the verb begrüßen, which requires an accusative object. But disambiguation takes place only after the adjunct clause (in bold), which contains the pronoun coreferent with Opernsängerinnen. In (6a) it is the accusative pronoun sie and in (6b) the dative pronoun ihnen. Schlesewsky (1996; cf. also Fanselow et al. 1999) demonstrated that disambiguation of Opernsängerinnen towards accusative case is harder if the coreferent dative pronoun $i h$ nen (6b) (rather than the accusative pronoun sie, $(6 a)$ ) intervenes between Opernsängerinnen and the verb begrüßen. In a self-paced reading task this was reflected in higher reading times at the disambiguating region (begrüßen sollte). Thus, sentences like (6a) with an accusative pronoun were easier to process than (6b). For disambiguation towards dative, the reverse was true - a dative pronoun facilitated processing. Apparently, processing is easier if the case of the pronoun matches that of its antecedent.

(6)

$\begin{array}{llllll}\begin{array}{l}\text { Der Tenor } \\ \text { The tenor.NOM }\end{array} & \begin{array}{l}\text { behauptet, } \\ \text { claims }\end{array} & \begin{array}{l}\text { dass } \\ \text { that }\end{array} & \begin{array}{l}\text { man } \\ \text { one }\end{array} & \begin{array}{l}\text { Opernsängerinnen, } \\ \text { opera singers.ACC }\end{array}\end{array}$

$\begin{array}{llllllll}\text { (a) obwohl } & \text { man } & \text { sie } & \text { erkennt, } & \text { begrüßen } & \text { sollte } & \ldots \\ \text { although } & \text { one } & \text { them.ACC } & \text { recognizes } & \text { greet } & \text { should } & \\ \text { obwohl } & \text { man } & \text { ihnen } & \text { misstraut, } & \text { begrüßen } & \text { sollte } & \ldots \\ \text { although } & \text { one } & \text { them.DAT } & \text { mistrusts } & \text { greet } & \text { should } & \end{array}$

'The tenor claims that one should greet opera singers, although one recognizes/mistrusts them.' 
The same effect held true for sentences such as (7), involving a restrictive relative clause instead of a parenthetic insertion.

(7)

$\begin{array}{llllll}\begin{array}{l}\text { Der Tenor } \\ \text { The tenor.NOM }\end{array} & \begin{array}{l}\text { behauptet, } \\ \text { claims }\end{array} & \begin{array}{l}\text { dass } \\ \text { that }\end{array} & \begin{array}{l}\text { man } \\ \text { one }\end{array} & \begin{array}{l}\text { Opernsängerinnen, } \\ \text { opera singerss.ACC }\end{array}\end{array}$

$\begin{array}{llllll}\text { (a) die } & \text { man } & \text { erkennt, } & \text { begrüßen } & \text { sollte } & \ldots \\ \text { who.ACC } & \text { one } & \text { recognizes } & \text { greet } & \text { should } & \\ \text { (b) denen } & \text { man } & \text { misstraut, } & \text { begrüßen } & \text { sollte } & \ldots \\ \text { who.DAT } & \text { one } & \text { mistrusts } & \text { greet } & \text { should } & \end{array}$

'The tenor claims that one should greet opera singers, who one recognizes/mistrusts.'

This phenomenon seems quite unexpected, given the reverse pattern in the findings of Babyonyshev and Gibson (1999) and Fedorenko et al. (2004). In their experiments, identical case marking did not facilitate but rather hindered processing. And thus it appears that coreference between the two NPs involved is a necessary precondition for case matching. And in fact, Fanselow et al. (1999) present evidence that this effect disappears if sie/ihnen is replaced by a second- or first person pronoun, thereby excluding coreference.

All interpretations of the case-matching effect involve the assumption that the unambiguous pronoun somehow affects the representation of the ambiguous NP such that it ends up having the same case as the pronoun before it is reanalyzed. According to Schlesewsky (1996), case matching is caused by the parser's tendency to unify as many features of coreferent NPs as possible, which serves as a disambiguation strategy; let us refer to this as the unification account. Fanselow et al. (1999) explain it by means of a grammatically motivated OT-constraint AGRCASE, which requires coreferent NPs to agree in case. Thus of the two readings of Opernsängerinnen the parser will adopt the one conforming to AGRCASE, leading to reanalysis effects at begrïßen in (6b) and (7b).

Bader and Meng (1999; cf. also Bader, Meng and Bayer, 2000; Bayer, Bader and Meng 2001) on the other hand relate case matching to number attraction. In their account, the head noun of an NP which does not bear a marked case may attract the case feature of a relative pronoun that it c-commands. According to them, both nominative and accusative are unmarked cases in German, while dative is marked. Critically, the attractor noun does not need to be ambiguous in order to attract a marked case feature - bearing an unmarked case is sufficient (Bader and Meng, 1999). In fact, ambiguous NPs in German are always compatible with unmarked case. Thus, under Bader and colleagues' view, case matching is expected to occur only in certain syntactic configurations in which an antecedent compatible with unmarked case precedes and c-commands a (relative) pronoun bearing a syntactically marked case. 
Critically, if percolation occurs only in an upward direction, attraction of marked case does not predict case matching to occur in the configuration in (8) and (9). In (8), [die Frau], which is assigned accusative case by the verb überrascht, serves as an antecedent for the next word, the locally ambiguous relative pronoun die. The relative pronoun's syntactic function is disambiguated only at the auxiliary hat/haben via number agreement. When the auxiliary is the singularmarked hat (in (8a)) the relative pronoun is disambiguated as the nominative subject; when the auxiliary is the plural-marked haben (in (8b)), the relative pronoun is disambiguated as the accusative object (the subject is now [die Männer]).

(8)

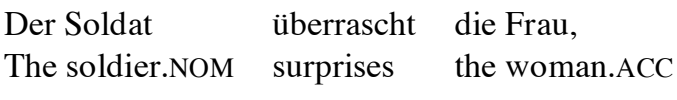

(a) die glücklicherweise die Männer besucht hat, who.NOM/ACC luckily the men.ACC/NOM visited AUX.SG

(b) die glücklicherweise die Männer besucht haben, who.ACC/NOM luckily the men.NOM/ACC visited AUX.PL

'The soldier surprises the woman who, luckily, has visited the men./

The soldier surprises the woman who, luckily, the men have visited.'

(9)

Das ist die Frau,

this is the woman.NOM

(a) die glücklicherweise die Männer besucht hat, who.NOM/ACC luckily the men.ACC/NOM visited AUX.SG

(b) die glücklicherweise die Männer besucht haben, who.ACC/NOM luckily the men.NOM/ACC visited AUX.PL

'That's the woman who, luckily, has visited the men./

That's the woman who, luckily, the men have visited.'

Example (9) differs only in the case assigned to [die Frau]; here the copula assigns nominative case. The relative clauses are identical to the ones in (8). In (9), there should be no attraction of marked case, as assumed by Bader and colleagues'. That is because dative case is not involved in this construction and thus no marked case can be attracted.

However, Schlesewsky (1996, also reported in Fanselow et al., 1999) showed that the processing time for the auxiliary depends on the case match between the relative pronoun and its antecedent. If it does match, like in (8b) and (9a), processing is easier than in the non-matching counterpart. Thus the disambiguating auxiliary was read more slowly in (8a) than in (8b), while (9a) was read faster than (9b). In other words, the case marking percolates downwards from die Frau to the relative pronoun die, which is incompatible with the Bader et al. account because 
(a) no marked case is involved and (b) attraction only supposed to happen in upward direction, but here [die Frau] c-commands the relative pronoun that it biases. It follows that case matching does not depend on any particular linearization of pronoun and antecedent, which favors the unification account over case attraction.

\subsection{Case matching and conflicting bindings}

But how does case matching relate to conflicting bindings? Let us recall the effect of CBRI: Similarities of dissimilar objects and dissimilarities of similar objects have an adverse effect on the retrieval latency. Coreferent NPs can be considered very similar by virtue of sharing the same discourse referent. Obviously, they may differ in syntactic and lexical properties (as they do in (6-9)), but they are as close to identity as possible for two different objects. Therefore the slowdown in processing due to mismatching case is not unexpected, given that dissimilarities of similar objects make retrieval harder.

If CBRI is the mechanism underlying case matching, we would expect the same effect even without coreference as long as we allow for enough similarity between the NPs. Importantly, Fanselow et al. (1999) as well as Schlesewsky (1996) would not predict such an effect, since both accounts rely on an anaphoric relationship between the NPs involved.

To test the opposing predictions of CBRI and the unification account, we conducted experiments $1 \mathrm{a}$ and $1 \mathrm{~b}$. We used a partitive construction referring to a proper subset of its antecedent. We used stimuli like (10) which contained a case ambiguous conjunctive NP Leo and Tim $(=N P 1)$ followed by a concessive clause (,obwohl ...,) containing the partitive construction one of them (=NP2). In a factorial design the case of NP1 was crossed with the case of NP2, and the case of the former was not resolved until the second verb ( grüßen, which assigns dative case to its object; and glauben, which assigns accusative case). If CBRI is the explanation for case matching, then (10c) should be harder to process than (10a) and (10b) harder than (10d). The processing difficulty should occur at the second verb, because it is here that the ambiguous NP is disambiguated/retrieved.

Additionally, this design allowed us to directly contrast the predictions from CBRI with predictions of coreference-based accounts. Although the partitive construction einen/einem von ihnen varied in case, it always contained the pronoun ihnen, bearing dative case. Thus, if case matching phenomena are driven by coreference, we would expect the ambiguous NP to be biased towards dative in all conditions. This should lead to a processing difficulty if the ambiguity is resolved to accusative - thereby making conditions $(10 \mathrm{a}, \mathrm{c})$ harder to process than $(10 \mathrm{~b}, \mathrm{~d})$. 
(10)

(a) Dass er [Leo und Tim $]_{\mathbf{i}}$, that he Leo and Tim

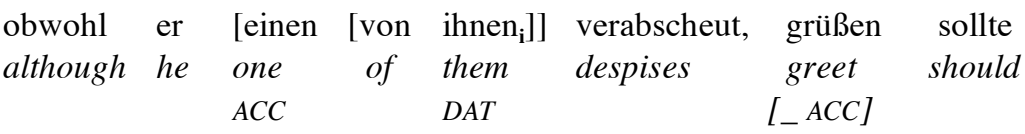

(b) Dass er [Leo und Tim $]_{\mathrm{i}}$, obwohl er [einen [von ihnen $\left.\left.{ }_{i}\right]\right]$ that he Leo and Tim although he one of them verabscheut, glauben sollte ACC/DAT ACC $D A T$ believe should

(c) Dass er [Leo und Tim $]_{\mathbf{i}}$, that he Leo and Tim obwohl er [einem [von ACC/DAT although he one of

ihnen $\left.\left._{\mathbf{i}}\right]\right]$

(d) Dass er [Leo und Tim $]_{\mathrm{i}}$, that he Leo and Tim

obwohl er DAT

ther grüßen sollte ACC/DAT although he

[einem [von ihnen

glaubt Sebastian nicht.

'Sebastian does not think, that he should greet/believe Tim and Leo, although he despises/mistrusts one of them.'

Importantly, CBRI's predictions rely on the assumption that the memory representation of morphologically ambiguous NPs consists of several distinct objects (chunks) and disambiguation involves retrieving the correct one. In principle, the parser could apply some sort of heuristic in order to tentatively resolve an ambiguity (cf. e.g. Bader et al 2000, Hopf et al 2003 inter alia). In this case the ambiguous NP would be represented by one chunk, which should suffer CBRI from a pronoun of a different case. Consequently, there should be a main effect of the first verb's (V1) case, but no case matching effect. Another possibility is to represent an ambiguous NP by means of one chunk with an underspecified case feature but again no case matching effect is to be expected, because since it is always the same chunk being retrieved, it should always suffer the same amount of interference, independent of the case it is finally disambiguated towards. So the CBRI account is not compatible with a single-chunk representation of ambiguous NPs, it requires case ambiguities to be represented by several chunks corresponding to their respective possibilities for disambiguation. Thus, evidence in favor of similarity as the driving force behind case matching would also constitute evidence in favor of a parallel representation of (some) ambiguities.

To recapitulate, a CBRI-based account of case matching predicts processing difficulty when the case of the ambiguous NP turns out to bear a different case than the partitive construction. Hence $(10 \mathrm{~b}, \mathrm{c})$ should be read more slowly than 
(10a,d). Accounts based on coreference, on the other hand, predict a slowdown when the ambiguous NP is resolved towards accusative, since the coreferent pronoun, which is part of the partitive construction is marked as dative. In this case $(10 a, c)$ should be read slower than $(10 d, b)$.

In order to test these predictions we conducted an eye-tracking experiment as well as an additional self-paced reading experiment and a plausibility rating study. 6

\subsubsection{Experiment 1a (eye-tracking)}

\section{Participants}

Fifty-six undergraduate students from University of Potsdam participated in exchange for course credit or a payment of $7 €$.

\section{Procedure}

Both filler and target materials were presented as whole texts on a single line. Participants were seated $55 \mathrm{~cm}$ from a 17" color monitor with $1024 \times 768$ pixel resolution. They were asked to sit comfortably in front of an IView-X eye-tracker (SensoMotoric Instruments) running at $240 \mathrm{~Hz}$ sampling rate, 0.025 degree tracking resolution, $<0.5$ degree gaze position accuracy. They were asked to place their head in a frame and to position their chin on a chin-rest for stability. Viewing was binocular, but only the participant's right eye was tracked. Participants were asked to avoid large head movements throughout the experiment. The presentation of the materials and the recording of responses was controlled by two PCs running proprietary software. Each participant was randomly assigned one of four pseudorandomized sentence lists.

At the start of the experiment the experimenter performed a standard calibration procedure, which involved participants looking at a grid of thirteen fixation targets in random succession in order to validate their gazes. Calibration and validation were repeated after every 10-15 trials throughout the experiment, or if the experimenter noticed that measurement accuracy was poor (e.g., after large head movements or a change in the participant's posture). Participants had the op-

\footnotetext{
6 The self-paced reading method was used to ensure comparability of our results with the results obtained by Schlesewsky (1996) and Fanselow et al. (1999). The plausibility rating study on the other hand, served to exclude potential systematic differences in plausibility caused by the fact that the proposition of the sentence was not constant across conditions.
} 
portunity to take a break if they felt tired.

Each trial was structured in the following way: First, a fixation target in the same position as the first character of the text display was presented; a fixation on this target triggered the presentation of the sentence. This ensured that participants always started reading in the leftmost character position. Each sentence was presentented in one line. Participants were instructed to read the sentence at a normal pace and to click a mouse button after finishing the sentence. To ensure that sentences were read for comprehension this was followed by a simple comprehension question, which the participant answered with 'yes' or 'no' by clicking one of two boxes on the screen. Responding to the question triggered the presentation of the next trial. A complete session took about $45 \mathrm{~min}$ to complete.

\section{Stimuli}

The stimuli consisted of 16 sets of items such as (10). The four conditions resulting from crossing the factors VI case (case assigned by the first verb to the partitive construction) and V2 case (case assigned by the second verb to the ambiguous NP) were divided into 4 pseudo-randomized lists using a latin-square design. They were intermixed with 70 fillers and 32 sentences from another, unrelated, experiment. The questions were targeted at either the matrix or embedded verb, or at the matrix or embedded clause object. In the latter case they focused on whether the proposition applies to one or both individuals. ${ }^{7}$

\section{Results}

Before we turn to the analyses of experimental data, we would like to present an overview of the eye tracking measures we used, together with their definition and the interpretation we attribute to them (cf. Table 9.1).

— Insert Table 9.1 about here.

We analyzed first-pass reading time (FPRT), regression-path duration (RPD), total-fixation time (TFT) and regression probability (RP) at the region comprising the disambiguating verb (grïßen/glauben in (8)) and the auxiliary. ${ }^{8}$ Additionally, we made use of regressive refixation probability $\left(\mathrm{RRP}_{\mathrm{verb}}\right)$ and regressive rereading time $\left(\mathrm{RRT}_{\mathrm{verb}+}\right)$ at the locally ambiguous $\mathrm{NP}$ and the partitive construction after disambiguation, i.e. subsequent to a fixation on the disambiguating verb or anything to the right of it. We did not exclude data from trials followed by a

\footnotetext{
7 These questions were meant to direct the participants' attention to the fact that the embedded clause object was a partitive construction and not a pronoun.

${ }^{8}$ If the verb was preceded by an adverb (in two items), it was included in the region too. One item lacked an auxiliary, and so the region consisted of the verb only.
} 
wrong response because interference may lead to different levels of accuracy. If online effects and accuracy are interdependent then considering only correct responses may distort the data instead of removing noise. The dependent measures were computed with the R package em (Logačev and Vasishth, 2006). All reading times were log-transformed before analysis. Reading times recorded as zero were excluded.

A mixed-effects model (Bates and Sarkar, 2007; Gelman and Hill, 2007) was fit with participants and items as crossed random factors, and V1 case and V2 case as fixed factors. No significant effects were found at the ambiguous NP an the partitive construction, although there was a marginally significant effect of V1 in regressive re-reading time on the partitive construction $(\mathrm{t}=1.82)$ due to longer re-reading times on dative partitive constructions. Additionally, there was a marginally significant interaction between V1 case and V2 case in regressive refixation probability $(\mathrm{t}=1.64)$ due to more regressions to the partitive construction if $\mathrm{V} 1$ case did not match V2 case. At the disambiguating verb region we found a significant interaction in regression-path duration $(\mathrm{t}=-2.00)$ and regression probability $(\mathrm{t}=2.11)$; both due to longer reading times respectively more regressions if $\mathrm{V} 1$ case did not match V2 case (i.e. in conditions $(10 c, d)$ ). There was no main effect at the disambiguating region $(|t|<1.5)$. There were no significant effects in comprehension accuracy.

Insert Table 9.2a about here.

- Insert Table 9.2b about here.

- Insert Table 9.3a about here.

- Insert Table 9.3b about here.

- Insert Table 9.4 about here.

Discussion will be postponed until after Experiment 1c.

\subsubsection{Experiment $1 b$ (self-paced reading)}

\section{Participants}

Forty-eight undergraduate students from University of Potsdam participated in exchange for course credit or a payment of $5 €$.

\section{Stimuli}


The stimuli were almost identical to the ones in Experiment 1a, but adapted to match in the number of words at and before the critical region. They were divided into 4 lists using a Latin-square design, intermixed with 70 fillers and 32 sentences from another, unrelated, experiment. The lists were randomized for every participant.

\section{Procedure}

The task was self-paced non-cumulative word-by-word reading. Presentation and recording was done with the Linger software package, version 2.94 by Doug Rohde running on an iMac G4. At the beginning of a trial the whole sentence appeared, masked by dashes. Participants pressed the space bar to reveal the next word. As the next word appeared, the current one was masked by dashes again. The time between key-presses was recorded as the reading time for the word. To ensure reading comprehension, each sentence was followed by a question - which participants had to answer with 'yes' or 'no' by pressing the corresponding button on the keyboard.

\section{Results}

A mixed-effects model (Bates and Sarkar, 2007; Gelman and Hill, 2007) was fit with participants and items as crossed random factors and revealed no significant effects at the disambiguating region $(|t| s<1.5)$. Visual inspection of the data suggested a case matching effect at the two words following the verb. Analysis of the reading time on these two words revealed a significant interaction $(\mathrm{t}=-2.38)$ due to mismatching conditions $(10 \mathrm{~b}, \mathrm{c})$ being read more slowly. There were no main effects $(|t| s<1)$. There were no significant effects in comprehension accuracy.

Insert Table 9.5a about here.

Insert Table $9.5 \mathrm{~b}$ about here.

Insert Table 9.6 about here.

Discussion will be postponed until after Experiment 1c.

\subsubsection{Experiment 1c (plausibility rating)}

To ensure that the effect found in Experiments 1a and 1b was really an on-line effect, i.e. that it was not accidentally caused by degraded plausibility of condi- 
tions $(10 \mathrm{~b}, \mathrm{c})$ we conducted an offline plausibility rating study.

\section{Participants}

Forty-eight undergraduate students from University of Potsdam participated in exchange for course credit.

\section{Stimuli}

The same stimuli as in the self-paced reading experiment were used. Using a latin-square design they were divided into 4 pseudo-randomized lists, intermixed with 70 fillers and 24 sentences from another, unrelated, experiment.

\section{Procedure}

Participants worked through a paper questionnaire rating sentences on a 7-point scale, ranging from 1 (completely implausible) to 7 (perfectly plausible).

\section{Results}

Insert Table 9.7 about here.

A mixed-effects model (Bates and Sarkar, 2007; Gelman and Hill, 2007) was fit with participants and items as crossed random factors and revealed no significant effects whatsoever.

\subsubsection{Discussion}

In both on-line experiments we found no evidence for coreference as the trigger of case matching effects. If coreference was the trigger, there should have been a processing disadvantage for accusative matrix verbs, i.e. a main effect of V2 case. There was none. Instead, we found an interaction between V1 case and V2 case, such that mismatching conditions were read more slowly. In Experiment 1a the slowdown occurred due to regressions, while in Experiment $1 \mathrm{~b}$ it occurred at the two words following the disambiguating verb, suggesting a spill-over effect. These slowdowns match the predictions of the similarity-based CBRI account, which predicts that even partitive constructions can cause case matching effects by 
virtue of similarity with the antecedent. The results of an off-line plausibility rating study suggest that this effect is not due to degraded plausibility in the mismatching conditions.

Interestingly, neither the probability of regressions to the ambiguous NP, nor the time spent on it given a regression, show any effect of our case manipulation. Under a unification or attraction account this finding is surprising, given that Frazier and Rayner (1982), Meseguer, Carreiras and Clifton (2002), inter alia, have demonstrated that reanalysis triggers more regressions towards the string to be reanalyzed. Thus, on the one hand our data suggests that case matching phenomena do not involve reanalysis, and on the other hand it shows that strict coreference is not a necessary condition for case matching - (strong) similarity seems sufficient. Both findings cannot be explained by unification or attraction theories, favoring an explanation in terms of CBRI.

So it is tempting to conclude that CBRI is the mechanism underlying case matching. If correct, an interesting conclusion from this unified explanation of interference and case matching is that morphological ambiguities must be represented by several chunks, i.e. in parallel. If an ambiguous NP was represented as one single object, the same object would have to be retrieved upon disambiguation - independent of the reading disambiguated towards. Thus, the amount of retrieval interference would always be the same and we would not observe any differences in processing times in (10). CBRI can only explain the findings at hand if a case ambiguous NPs is stored in form of several chunks, each causing a different amount of interference. Since other accounts, however, do not appear to explain the present data, it does seem reasonable to adopt this assumption.

\subsection{Case?}

Experiments $1 \mathrm{a} \& 1 \mathrm{~b}$ have a weak point. As in most other experiments on case matching, varying the case of an NP involved varying the verb, and therefore the proposition of the sentence. Although we tried to keep the meaning of each accusative-dative verb pair as close as possible and although we made sure that there is no detectable difference in plausibility, we cannot rule out a systematic variation in our verbs such that arguments of each verb class share more properties than just the case.

German dative objects of two-place verbs differ from accusative objects not only in syntactic behavior (Fanselow, 2000; McFadden, 2006), but also in semantic properties. They cover different ranges of possible thematic roles. For example, according to Primus (1999), dative cannot be assigned to objects physically affected by the action denoted, while accusative can. Also, accusative objects tend to have more Proto-Patient properties, while dative objects often have some ProtoAgent properties. Thus, we cannot be certain the possibility that the interference or case matching effect observed in Experiment 1 is really caused by case. Instead, it may be brought about by additional properties, which tend to go with accusative 
or dative case respectively.

To address this issue and to investigate the influence of case marking while holding the theta-roles and the proposition sufficiently constant, we conducted Experiment 2. Quite similar to the stimuli in (8) and (9), our stimuli consisted of a main clause with a relative clause attached to either the object of an active sentence or the subject of a passive sentence (die Künstler in (11) and (12) respectively). Moreover, the relative clause had either subject-object - ((11a) and (12a)) or object-subject order ((11b) and (12b)). It was always attached to the same NP ("die Künstler"), which always had the same theta role. Only the antecedent's grammatical function and therefore its case was varied in the main clause. In (11) it was an object in accusative case, whereas in (12) it was the subject, therefore bearing nominative case. Since we used feminine and plural NPs, the case was not overtly marked since both types of NPs have the same morphological marking for nominative and accusative. Abstract case was disambiguated by the first NP in the main clause.

Importantly, the grammatical functions in the relative clause were ambiguous and only resolved at its final word, the auxiliary. The ambiguity was resolved by number agreement, and to this end the arguments differed in number.

(11)

$$
\begin{array}{lll}
\text { Der Prinz } & \text { respektiert } & \text { die Künstler } \\
\text { the prince.NOM } & \text { respects } & \text { the artists.ACC }
\end{array}
$$
(a) die
die Königin
who.NOM/ACC
the queen.ACC/NOM
(b) die
die Königin
who.acc/nom
the queen.nom/acc
$\begin{array}{ll}\text { erst } & \text { kürzlich } \\ \text { only } & \text { recently } \\ \text { erst } & \text { kürzlich } \\ \text { only } & \text { recently }\end{array}$
met
.. für ihr
herausragendes
for their outstanding talent
Talent.
'The prince respects the artists, who the queen only recently visi- ted/who only recently visited the queen, for their outstanding talent.'

getroffen

haben

getroffen HAT

(12)

Vom Prinzen respektiert werden die Künstler ... by the prince respected AUX.PASS the artists.NOM

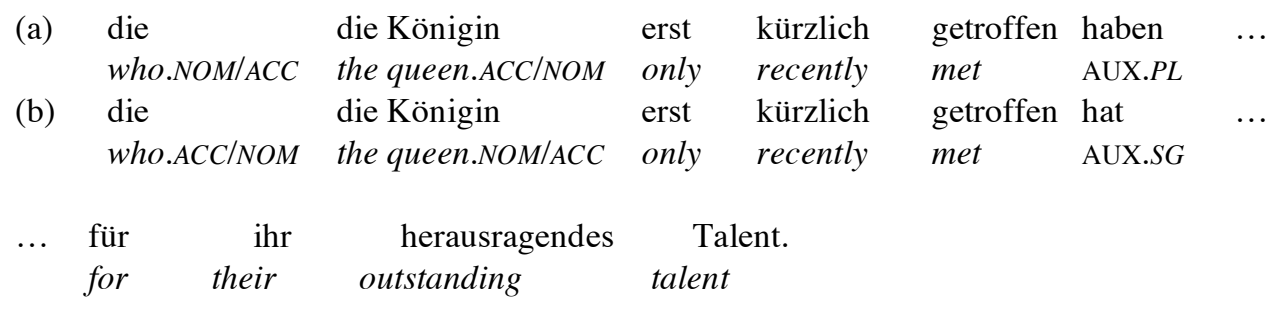


'The artists, who the queen only recently visited/who only recently visited the queen, are respected by the prince for their outstanding talent.'

If case matching is really case matching proper, we expect an interaction in reading times at the point of disambiguation (hat/haben). In contrast to the wellattested preference for subject-object (SO) word order (e.g. Kaan, 1997;

Kretzschmar, this volume; Lamers 2001, 2005, see also this volume; Mak et al., 2006; Scheepers et al., 2000; Schlesewsky et al., 2000) we expect that SO order is only preferred if the antecedent is nominative while OS order is preferred if it is accusative. Therefore (11b) should be processed faster than (11a) while (12b) should be processed slower than (12a). If, on the other hand, case matching is caused by something which is not case proper, but rather something which may be confounded with it (e.g. affectedness, awareness, control, etc.) we expect there to be no effect of the main clause on the word order preference within the relative clause. There should be an across-the-board SO preference, making (11a) and (12a) easier to process than (11b) and (12b).

To avoid a confound and ensure that a case matching effect is not predicted by structural frequencies, we investigated the TIGER corpus (König and Lezius, 2003) in order to determine how the case of a relative pronoun depends on its antecedent's case. We made two searches: one for all NPs headed by proper nouns (cf. Table 9.6a) and one for a subset consisting only of feminine NPs (Table $9.6 b)$ to make sure that the results generalize to case-ambiguous NPs. Clearly, independent of the antecedent case relative pronouns tend to be nominative.

Insert Table 9.8a about here.

Insert Table $9.8 \mathrm{~b}$ about here.

\subsubsection{Experiment 2}

\section{Participants}

Fifty-six undergraduate students from University of Potsdam participated in exchange for course credit or a payment of $7 €$.

\section{Stimuli}


Crossing the factors antecedent case and relative pronoun case resulted in 4 experimental conditions, which we implemented in 24 sets of items such as (11) and (12). In half the items the antecedent (and therefore relative pronoun) was singular, in the other half it was plural. To allow for disambiguation by number, the other NP in the relative clause differed in number. The items were divided into 4 pseudo-randomized lists using a Latin-square design and intermixed with 96 sentences from other, unrelated experiments.

\section{Procedure}

The procedure was identical to the one in Experiment 1a.

\section{Results}

We analyzed first-pass reading time (FPRT), regression-path duration (RPD), total-fixation time (TFT), regression probability (RP), and regressive refixation probability (RRP) at the verb, and the auxiliary. Furthermore we examined regressive refixation probability and regressive re-reading time at the relative pronoun and the RC-internal NP subsequent to disambiguation, i.e. after a fixation on the verb (due to possible preview effects of the auxiliary), the auxiliary itself, or anything to the right of it $\left(\mathrm{RRP}_{\text {verb+ }}\right.$ and $\left.\mathrm{RRT}_{\text {verb+ }}\right)$. We hypothesize that these measures at these regions reflect the degree of processing difficulty that may be caused by mismatching case.

The dependent measures were computed with the R package $\mathrm{em}$ (Logačev and Vasishth, 2006). All reading times were log-transformed before analysis. Reading times recorded as zero were excluded. A mixed-effects model (Bates and Sarkar, 2007; Gelman and Hill, 2007) was fit with participants and items as crossed random factors. It revealed a marginally significant effect of relative pronoun case in regressive re-reading time $(\mathrm{t}=1.66)$ at the relative pronoun caused by longer reading times for accusative relative pronouns. No significant effects were found for the RC-internal NP.

There was a significant interaction in regression probability at the verb $(\mathrm{t}=-2.75)$ and the auxiliary $(\mathrm{t}=-2.61)$ due to more regressions when relative pronoun case and antecedent case did not match (i.e. (11a) and (12b)). The same pattern was present in regressive refixation time at the verb (more refixations if relative pronoun case does not match antecedent case, $t=-1.96)$. Furthermore, there was an interaction at the auxiliary in regression path duration $(\mathrm{t}=-2.48)$ and (marginally significant) in first-pass reading time $(\mathrm{t}=-1.79)$ due to longer reading times if the antecedent case did not match the relative pronoun case. There were no significant effects for comprehension accuracy. 
- Insert Table 9.10a about here.

- Insert Table 9.10b about here.

Insert Table 9.11 about here.

\subsubsection{Discussion}

Regression probability at the verb and auxiliary, as well as reading times at the auxiliary that the subject preference for the relative pronoun (i.e. subject-object word order for the RC) does not only become weaker, but even reverses when the relative pronoun's antecedent is accusative. Because the only features manipulated in the main clause were (abstract) case and therefore grammatical function, it appears that they are sufficient to induce case matching effects. Therefore, no additional properties associated with case need to be taken into account for explaining the outcome of Experiment 1. It therefore seems safe to conclude that it is these syntactic factors which underlie case matching phenomena.

Furthermore, the lack of regressions to the ambiguous NPs in the mismatching conditions (11a) and (12b) is quite in line with the results of Experiment 1a, and again suggest that reanalysis is not involved in processing of sentences with mismatching case. Again, this pattern favors a retrieval account such as CBRI over unification or attraction accounts.

\subsection{Conclusion}

We began by reviewing two different types of interference theories that have been proposed in the literature: (a) Van Dyke and McElree's interference due to retrieval-cue overlap, and (b) Gordon and colleagues' interference due to match in referential properties. We argued that these two theories address orthogonal phenomena and are unable to provide a unified explanation for the full range of results that fall under the rubric of interference. Further, we showed that none of the existing theories can explain the surprising fact that a match between two noun phrases along two dimensions can facilitate rather than hinder processing (similarity-based facilitation); current theories make the opposite prediction. We proposed an explanation based on an assumption about the nature of memory representations: conflicting bindings. We showed that, under this representational assumption, not only can we explain the published similarity-based interference facts but also the similarity-based facilitation data. In addition, we demonstrated that the conflicting-bindings assumption can also furnish an explanation for case matching phenomena in German.

In particular, in Experiment 1 we showed that strong similarity is suffi- 
cient to trigger case matching effects. Coreference is not really necessary. The outcome of Experiment 2 suggests that it is not properties tentatively associated with case (e.g. affectedness, control) but rather (abstract) case proper, which is responsible for case matching. The importance of similarity can be explained in terms of CBRI, a memory mechanism for which there is independent evidence. Under this account, a case ambiguity has to be represented by several chunks in WM, each with a different case feature. Disambiguation involves retrieving the correct one, using the case assigned to the NP as a retrieval cue. This retrieval process is harder if the case feature of the to-be-retrieved chunk does not match the case feature of another, highly similar, NP present in WM (coreferent pronoun or partitive construction in the examples so far). Since every feature of an object is bound to every other one, most of the bindings involving the mismatching case feature will be conflicting. More precisely, it will be the ones binding the case feature to other features shared by both objects. If the case feature, however, matches, they will be identical in both objects. Only the smaller number of bindings between the case feature and features not shared by both objects will be conflicting. Therefore, sentences with two similar NPs bearing same case are easier to process, since retrieving a chunk with a matching case feature will be easier. Two dissimilar NPs, however, will be harder to process if they bear the same case, since it will give rise to retrieval interference at the verb.

In sum, in contrast to SBI, conflicting binding based retrieval interference can explain Fedorenko et al.'s data as well as case matching. Gordon et al.'s explanation based on 'referential properties' can be subsumed under the similarity account as well as under the quite plausible assumption that objects of different types will be associated with different features or feature bundles representing their type, or the attributes associated with their particular type. One important implication is that different readings of case ambiguous NPs must be represented by distinct chunks before disambiguation.

To sum up, we have presented an independently motivated storage and retrieval mechanism based on bindings, which offers a unification of apparently unrelated, or even contradicting phenomena.

\section{REFERENCES}

Anderson, J. R. \& Paulson, R. (1978). Interference in memory for pictorial information. Cognitive Psychology, 9, 178-202.

Babyonyshev, M. \& Gibson E. (1999). The complexity of nested structures in Japanese. Language, 75, 423-450.

Bader, M. (1996): Sprachverstehen. Opladen: Westdeutscher Verlag.

Bader, M., \& Meng, M. (1999). Case Attraction Phenomena in German. Unpublished Manuscript. Univerity of Jena.

Bader, M., Meng, M., \& Bayer, J. (2000). Case and reanalysis. Journal of Psycholinguistic Research, 29, 37-52. 
Bates, D., \& Sarkar, D. (2007). lme4: Linear mixed-effects models using S4 classes (R package version 0.9975-11) [Computer software].

Bayer, J., Bader, M., \& Meng, M. (2001). Morphological underspecification meets oblique case: Syntactic and processing effects in German. Lingua, 111, 465-514.

Clifton, C., Juhasz, B., Ashby, J., Traxler, M. J., Mohamed, M. T., Williams, R. S., et al. (2003). The use of thematic role information in parsing: Syntactic processing autonomy revisited. Journal of Memory and Language, 49, 317-334.

Clifton, C., Staub, A., \& Rayner, K. (2007). Eye Movements in Reading Words and Sentences. In R. V. Gompel, M. Fisher, W. Murray, \& R. L. Hill (Eds.), Eye movements: A window on mind and brain. Amsterdam: Elsevier., 341-372.

Colzato, L. S., Raffone, A., \& Hommel, B. (2006). What do we learn from binding features? Evidence for multilevel feature integration. Journal of Experimental Psychology: Human Perception and Performance, 32, 705-716.

Fanselow, G. (2000). Optimal exceptions. In B. Stiebels \& D. Wunderlich (Eds.), Lexicon in focus. Berlin: Akademie Verlag., 173-209.

Fanselow, G., Schlesewsky, M., Cavar, D. \& Kliegl, R. (1999). Optimal Parsing: Syntactic parsing preferences and optimality theory. Rutgers Optimality Archive, 367-1299.

Fedorenko, E., Babyonyshev, M., \& Gibson, E. (2004). The Nature of Case Interference in Online Sentence Processing in Russian. NELS 34 Conference Proceedings.

Frazier, L., \& Rayner, K. (1982). Making and correcting errors during sentence comprehension Eye movements in the analysis of structurally ambiguous sentences. Cognitive Psychology, $14,178-210$.

Gelman, A., \& Hill, J. (2007). Data analysis using regression and multilevel/hierarchical models. New York: Cambridge University Press.

Gordon, P.C., Hendrick, R., \& Johnson, M. (2001). Memory interference during language processing. Journal of Experimental Psychology: Learning, Memory and Cognition, 27, 14111423.

Gordon, P.C., Hendrick, R., \& Levine, W.H. (2002). Memory-load interference in syntactic processing. Psychological Science, 13, 425-430.

Hommel, B. (1998). Event files: Evidence for automatic integration of stimulus-response episodes. Visual Cognition, 5, 183-216.

Hommel, B., \& Colzato, L. S. (2004). Visual attention and the temporal dynamics of feature integration. Visual Cognition, 11, 483-521.

Hopf, J.-M., Bader, M., Meng, M., \& Bayer, J. (2003). Is human sentence parsing serial or parallel? Evidence from event-related brain potentials. Cognitive Brain Research, 15, 165-177.

Inhoff, A. W. (1984). Two stages of word processing during eye fixations in the reading of prose. Journal of Verbal Learning and Verbal Behavior, 23(5), 612-624.

Kaan, E. (1997). Processing Subject-Object Ambiguities in Dutch. PhD Thesis, University of Groningen

Kempen, G. \& Harbusch, K. (2005). The relationship between grammaticality ratings and corpus frequencies: A case study into word order variability in the midfield of German clauses. In: Kepser, Stephan \& Reis, Marga (Eds.), Linguistic Evidence - Empirical, Theoretical, and Computational Perspectives. Berlin: Mouton De Gruyter., 327-347.

König, E., \& Lezius, W. (2003). The TIGER language - a description language for syntax graphs, Formal definition (Tech. Rep.). Germany: IMS, Universität Stuttgart.

Lamers M.J.A. (2001). Sentence processing: using syntactic, semantic, and thematic information. $\mathrm{PhD}$ Thesis. Groningen.

Lamers M.J.A. (2005). Resolving subject-object ambiguities with and without case: evidence from ERPs. To appear in M. Amberber \& H. de Hoop (eds). Case-marking: competition and variation. Perspectives on Cognitive Science Series, 251-293.

Lewis, R. L. (1996). Interference in short-term memory: The magical number two (or three) in sentence processing. The Journal of Psycholinguistic Research 25:93-115.

Lewis, R.L. and Vasishth, S. (2005). An activation-based model of sentence processing as skilled memory retrieval. Cognitive Science, 29, 1-45. 
Lewis, R.L., Vasishth, S., and Van Dyke, J. (2006). Computational principles of working memory in sentence comprehension. Trends in Cognitive Sciences, 10(10), 447-454.

Logačev, P. \& Vasishth, S. (in preparation). Cue-less retrieval interference and facilitation. Ms, University of Potsdam.

Logačev, P., \& Vasishth, S. (2006). The em package for computing eyetracking measures.

Potsdam, Germany.

Mak, W.M., Vonk, W. \& Schriefers, H. (2006). Animacy in processing relative clauses: The hikers that rock crush. Journal of Memory and Language, 54 (4).

McElree, B. (2000). Sentence comprehension is mediated by content-addressable memory structures. Journal of Psycholinguistic Research, 29, 111-123.

McFadden, T. (2006): German inherent datives and argument structure. In Datives and similar cases, ed. Werner Abraham, Daniel Hole and André Meinuger. Amsterdam: John Benjamins.

Meseguer, E., Carreiras, M., \& Clifton, C., Jr. (2002). Overt reanalysis strategies and eye movements during the reading of mild garden path sentences. Memory \& Cognition, 30, 551-561.

Miller, G. A. \& N. Chomsky. 1963. Finitary Models of Language Users. Handbook of Mathematical Psychology Vol.II, eds. D. R. Luce, R. R. Bush, \& E. Galanter. New York: John Wiley.

Oberauer, K., \& Kliegl, R. (2006). A formal model of capacity limits in working memory. Journal of Memory and Language, 55, 601-626

Primus, B. (1999). Cases and thematic roles. Tübingen: Niemeyer.

Rayner, K., \& Pollatsek, A. (1987). Eye movements in reading: A tutorial review. Attention and performance XII: The psychology of reading, 327-362.

Schlesewsky, M. (1996). Kasusphänomene in der Sprachverarbeitung. PhD Thesis, Universität Potsdam.

Scheepers, C., Hemforth, B. \& Konieczny, L. (2000). Linking Syntactic Functions with Thematic Roles: Psych-Verbs and the Resolution of Subject-Object. In B. Hemforth \& L. Konieczny (Eds.), German sentence processing. Dordrecht: Kluwer., 65-93

Schlesewsky, M., Fanselow, G., Kliegl, R., \& Krems, J. (2000). The subject preference in the processing of locally ambiguous wh-questions in German. In B. Hemforth \& L. Konieczny (Eds.), German sentence processing. Dordrecht: Kluwer., 65-93

Suckow, K., Vasishth, S., \& Lewis, R. (2005). Interference and memory overload during parsing. Poster presented at the AMLaP conference, Ghent, Belgium.

Van Dyke, J.A. \& Lewis, R.L. (2003). Distinguishing effects of structure and decay on attachment and repair: A retrieval interference theory of recovery from misanalyzed ambiguities. Journal of Memory and Language, 49(3), 285-316.

Van Dyke, J. A., \& McElree, B. (2006). Retrieval Interference in Sentence Comprehension. Journal of Memory and Language, 55, 157-166.

Vasishth, S., Brüssow, S., Lewis, R.L. \& Drenhaus, H. (2008) Processing polarity: How the ungrammatical intrudes on the grammatical. Cognitive Science, 32 (4).

Vasishth, S. \& Lewis, R.L. (2006). Argument-head distance and processing complexity: Explaining both locality and antilocality effects. Language, 82(4):767-794.

Vasishth, S. (2008). Integration and prediction in head-final structures. In Processing and Producing Head-Final Structure. 


\begin{tabular}{|c|c|c|c|}
\hline Symbol & Measure & Definition & $\begin{array}{l}\text { Hypothesized Cognitive } \\
\text { Process }\end{array}$ \\
\hline FPRT & $\begin{array}{l}\text { first-pass reading } \\
\text { time, gaze dura- } \\
\text { tion }\end{array}$ & $\begin{array}{l}\text { the sum of all fixations in a region } \\
\text { during first pass }\end{array}$ & $\begin{array}{l}\text { text integration (Inhoff, } \\
\text { 1984) but cf. (Rayner \& Pol- } \\
\text { latsek, 1987) }\end{array}$ \\
\hline $\mathrm{RP}$ & $\begin{array}{l}\text { regression proba- } \\
\text { bility }\end{array}$ & $\begin{array}{l}\text { - likelihood of jumping back to a } \\
\text { previous word during the first pass }\end{array}$ & $\begin{array}{l}\text { resolution of temporary am- } \\
\text { biguity (Frazier \& Rayner, } \\
\text { 1982; Clifton et al., 2003) }\end{array}$ \\
\hline RPD & $\begin{array}{l}\text { regression path } \\
\text { duration }\end{array}$ & $\begin{array}{l}\text { the sum of all fixations from the } \\
\text { first fixation on the region of inte- } \\
\text { rest up to, but excluding, the first } \\
\text { fixation downstream from the regi- }\end{array}$ & $\begin{array}{l}\text { integration difficulty (Clif- } \\
\text { ton et al., 2007, 349) }\end{array}$ \\
\hline
\end{tabular}


on of interest

TFT total fixation timesum of all fixation durations of a general comprehension difword ficulty

$\mathrm{RRP}_{\mathrm{W}+} \quad$ regressive refixa- likelihood of jumping back to a processing difficulty assocition probability preceding word after reading word ated with a word, caused by $\mathrm{W}$ or anything further downstream $\mathrm{W}$

$\mathrm{RRT}_{\mathrm{W}+}$ regressive re- time spent reading a preceding re-processing difficulty asreading time word after a regression from word sociated with a word, caused $\mathrm{W}$ or anything further downstream by $\mathrm{W}$

Table 9.1: Definitions of eye-tracking measures and their interpretations.

\begin{tabular}{cllll}
\hline \multicolumn{1}{c}{ Condition } & $(10 \mathrm{a})$ & $(10 \mathrm{~b})$ & $(10 \mathrm{c})$ & $(10 \mathrm{~d})$ \\
Measure & & & & \\
\hline $\begin{array}{c}\text { Ambiguous NP } \\
\mathrm{RRP}_{\text {verb+ }}\end{array}$ & $.37(.03)$ & $.37(.03)$ & $.35(.03)$ & $.33(.03)$ \\
$\mathrm{RRT}_{\text {verb+ }}$ & $194(27)$ & $202(19)$ & $247(29)$ & $230(27)$ \\
Partitive Construction & & & & \\
$\mathrm{RRP}_{\text {verb+ }}$ & $.34(.03)$ & $.39(.03)$ & $.39(.03)$ & $.36(.03)$ \\
RRT $_{\text {verb+ }}$ & $241(27)$ & $266(31)$ & $355(42)$ & $287(39)$ \\
\hline
\end{tabular}

Table 9.2a: Eye-tracking measures at the ambiguous NP and the partitive construction, SE in brackets.

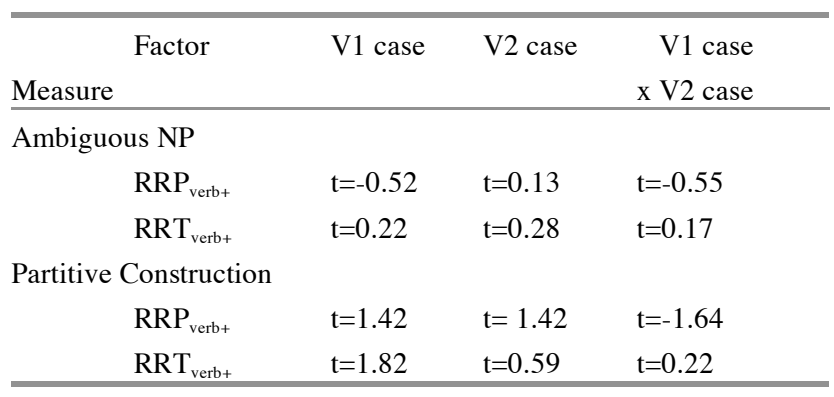

Table 9.2b: T-values for the ambiguous NP and the partitive construction.

\begin{tabular}{|c|c|c|c|c|c|}
\hline & Condition & (10a) & (10b) & (10c) & (10d) \\
\hline \multicolumn{6}{|l|}{ Measure } \\
\hline FPRT & & 149 (9) & $152(8)$ & $153(11)$ & $147(9)$ \\
\hline RPD & & $169(10)$ & $185(11)$ & 188 (14) & $175(12)$ \\
\hline
\end{tabular}




\begin{tabular}{lllll}
\hline TFT & $224(14)$ & $232(13)$ & $227(15)$ & $228(16)$ \\
RP & $.08(.02)$ & $.12(.02)$ & $.11(.02)$ & $.07(.02)$ \\
\hline
\end{tabular}

Table 9.3a: Eye-tracking measures at the disambiguating region, SE in brackets.

\begin{tabular}{|c|c|c|c|c|}
\hline Measure & Factor & V1 case & V2 case & $\begin{array}{r}\mathrm{V} 1 \text { case } \\
\mathrm{x} \mathrm{V} 2 \text { case }\end{array}$ \\
\hline FPRT & & $\mathrm{t}=0.65$ & $\mathrm{t}=1.14$ & $\mathrm{t}=-1.30$ \\
\hline RPD & & $\mathrm{t}=0.83$ & $\mathrm{t}=1.38$ & $\mathrm{t}=-2.0 \quad *$ \\
\hline TFT & & $\mathrm{t}=-0.45$ & $\mathrm{t}=0.49$ & $\mathrm{t}=-0.54$ \\
\hline $\mathrm{RP}$ & & $\mathrm{t}=1.07$ & $\mathrm{t}=1.28$ & $\mathrm{t}=-2.11 *$ \\
\hline
\end{tabular}

Table 9.3b: T-values for the disambiguating region.

\begin{tabular}{lllll}
\hline Condition & $(10 \mathrm{a})$ & $(10 \mathrm{~b})$ & $(10 \mathrm{c})$ & $(10 \mathrm{~d})$ \\
\hline Accuracy & $0.71(.03)$ & $0.67(.03)$ & $0.68(.03)$ & $0.69(.03)$ \\
\hline
\end{tabular}

Table 9.3: Comprehension questions accuracy, SE in brackets.

\begin{tabular}{lllll}
\hline \multicolumn{1}{c}{ Condition } & $(10 \mathrm{a})$ & $(10 \mathrm{~b})$ & $(10 \mathrm{c})$ & $(10 \mathrm{~d})$ \\
Position & & & & \\
\hline $\mathrm{V} 2$ & $619(25)$ & $591(20)$ & $589(26)$ & $606(24)$ \\
$\mathrm{V} 2+1$ & $625(35)$ & $663(34)$ & $652(33)$ & $613(30)$ \\
$\mathrm{V} 2+2$ & $498(16)$ & $505(17)$ & $515(16)$ & $481(15)$ \\
$\mathrm{V} 2+3$ & $446(13)$ & $457(16)$ & $433(11)$ & $442(11)$ \\
$\mathrm{V} 2+1$ and $\mathrm{V} 2+2$ & $1124(42)$ & $1168(40)$ & $1167(39)$ & $1094(37)$ \\
\hline
\end{tabular}

Table 9.5a: Reading times after the disambiguating region, SE in brackets.

\begin{tabular}{llll}
\hline Condition & $\mathrm{V} 1$ case & $\mathrm{V} 2$ case & \multicolumn{1}{c}{$\mathrm{V} 1$ case } \\
Position & & & $\mathrm{x}$ V2 case \\
\hline $\mathrm{V} 2$ & $\mathrm{t}=-0.87$ & $\mathrm{t}=0.28$ & $\mathrm{t}=1.37$ \\
$\mathrm{~V} 2+1$ & $\mathrm{t}=-0.57$ & $\mathrm{t}=-0.25$ & $\mathrm{t}=-1.56$ \\
$\mathrm{~V} 2+2$ & $\mathrm{t}=-0.29$ & $\mathrm{t}=-1.49$ & $\mathrm{t}=-1.68$ \\
$\mathrm{~V} 2+3$ & $\mathrm{t}=-0.88$ & $\mathrm{t}=0.74$ & $\mathrm{t}=0.30$ \\
$\mathrm{~V} 2+1$ and $\mathrm{V} 2+2$ & $\mathrm{t}=-0.51$ & $\mathrm{t}=-0.78$ & $\mathrm{t}=-2.38 *$ \\
\hline
\end{tabular}


Table 9.5b: T-values for the disambiguating region.

\begin{tabular}{lllll}
\hline Condition & $(10 \mathrm{a})$ & $(10 \mathrm{~b})$ & $(10 \mathrm{a})$ & $(10 \mathrm{~b})$ \\
\hline Accuracy & $0.69(.03)$ & $0.71(.03)$ & $0.77(.03)$ & $0.70(.03)$ \\
\hline
\end{tabular}

Table 9.6: Comprehension accuracy, SE in brackets

\begin{tabular}{|c|c|c|}
\hline V2 Case & Accusative & Dative \\
\hline \multicolumn{3}{|l|}{ V1 Case } \\
\hline Accusative & $5.25(.11)$ & $5.31(.11)$ \\
\hline Dative & $5.28(.10)$ & $5.12(.11)$ \\
\hline
\end{tabular}

Table 9.7: Embedded verb: means by condition, SE in brackets

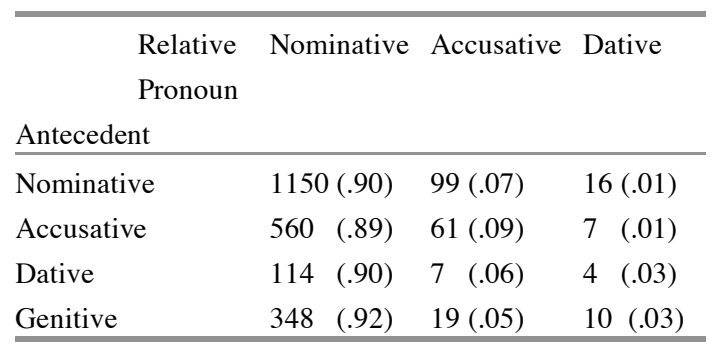

Table 9.8a: TIGER corpus count for the occurrence of all combinations of relative pronoun case and antecedent case (all NPs). Percentages in brackets.

\begin{tabular}{llll}
\hline $\begin{array}{l}\text { Relative } \\
\text { Pronoun }\end{array}$ & Nominative & Accusative & Dative \\
Antecedent & & & \\
\hline Nominative & $386(.90)$ & $35(.08)$ & $3(.01)$ \\
Accusative & $218(.90)$ & $21(.09)$ & $3(.01)$ \\
Dative & $35(.92)$ & $2(.05)$ & $1(.03)$ \\
Genitive & $123(.87)$ & $12(.09)$ & $6(.04)$ \\
\hline
\end{tabular}

Table 9.8b: TIGER corpus count for the occurrence of all combinations of relative pronoun case and antecedent case (only NPs). Percentages in brackets. 


\begin{tabular}{lllll}
\hline \multicolumn{1}{r}{ Condition } & $(11 \mathrm{a})$ & $(11 \mathrm{~b})$ & $(12 \mathrm{a})$ & $(12 \mathrm{~b})$ \\
Measure & & & & \\
\hline Relative Pronoun & & & & \\
$\mathrm{RRP}_{\text {verb+ }}$ & $.18(.02)$ & $.20(.02)$ & $.18(.02)$ & $.20(.02)$ \\
$\mathrm{RRT}_{\text {verb }}$ & $283(32)$ & $344(27)$ & $304(23)$ & $338(32)$ \\
$\mathrm{RRP}_{\text {verb+ }}$ & $.35(.03)$ & $.35(.03)$ & $.34(.03)$ & $.35(.03)$ \\
$\mathrm{RRT}_{\text {verb }}$ & $621(38)$ & $766(59)$ & $708(56)$ & $694(48)$ \\
\hline
\end{tabular}

Table 9.9a: Eye-tracking measures at the relative pronoun and the $\mathrm{RC}$-internal $\mathrm{NP}, \mathrm{SE}$ in brackets.

\begin{tabular}{clll}
\hline \multicolumn{1}{c}{ Factor } & Antecedent Case & Relative Pronoun Case & $\begin{array}{c}\text { Antecedent Case } \\
\text { x Relative Pronoun Case }\end{array}$ \\
Measure & & & \\
\hline $\begin{array}{c}\text { Relative Pronoun } \\
\operatorname{RRP}_{\text {verb+ }}\end{array}$ & $\mathrm{t}=-0.17$ & $\mathrm{t}=1.01$ & $\mathrm{t}=0.34$ \\
$\operatorname{RRT}_{\text {verb }}$ & $\mathrm{t}=-0.81$ & $\mathrm{t}=1.66$ & $\mathrm{t}=0.57$ \\
RC-internal NP $_{\operatorname{RRP}_{\text {verb+ }}}$ & $\mathrm{t}=0.21$ & $\mathrm{t}=0.36$ & $\mathrm{t}=0.07$ \\
$\operatorname{RRT}_{\text {verb }}$ & $\mathrm{t}=0.05$ & $\mathrm{t}=0.29$ & $\mathrm{t}=-0.67$ \\
\hline
\end{tabular}

Table 9.9b: T-values for the disambiguating region.

\begin{tabular}{|c|c|c|c|c|c|}
\hline & Condition & (11a) & $(11 b)$ & (12a) & $(12 b)$ \\
\hline \multicolumn{6}{|c|}{ Measure } \\
\hline \multicolumn{6}{|l|}{ Verb } \\
\hline & FPRT & $116(5)$ & $124(6)$ & $116(5)$ & $123(6)$ \\
\hline & RPD & $146(7)$ & $141(8)$ & $137(6)$ & $150(8)$ \\
\hline & TFT & $181(9)$ & $180(9)$ & $178(9)$ & $195(10)$ \\
\hline & $\mathrm{RP}$ & $.15 \quad(.02)$ & $.08 \quad(.02)$ & $.10 \quad(.02)$ & $.13 \quad(.02)$ \\
\hline & RRP & $.40 \quad(.03)$ & $.32(.03)$ & $.38 \quad(.03)$ & $.39 \quad(.03)$ \\
\hline \multicolumn{6}{|c|}{ Auxiliary } \\
\hline & FPRT & $94(5)$ & $87(4)$ & $90(5)$ & $93(4)$ \\
\hline & RPD & $139(11)$ & $117(10)$ & $120(9)$ & $132(11)$ \\
\hline
\end{tabular}




\begin{tabular}{lllllllll}
\hline TFT & 133 & $(8)$ & 123 & $(7)$ & 121 & $(7)$ & 137 & $(8)$ \\
RP & .20 & $(.02)$ & .13 & $(.02)$ & .14 & $(.02)$ & .19 & $(.02)$ \\
RRP & .27 & $(.03)$ & .29 & $(.03)$ & .24 & $(.03)$ & .28 & $(.03)$ \\
\hline
\end{tabular}

Table 9.10a: Eye-tracking measures at the disambiguating region, SE in brackets.

\begin{tabular}{|c|c|c|c|}
\hline $\begin{array}{l}\text { Factor } \\
\text { Measure }\end{array}$ & Antecedent Case & Relative Pronoun Case & $\begin{array}{l}\text { Antecedent Case } \\
\text { x Relative Pronoun Case }\end{array}$ \\
\hline \multicolumn{4}{|l|}{ Verb } \\
\hline FPRT & $\mathrm{t}=-0.21$ & $\mathrm{t}=1.24$ & $\mathrm{t}=1.01$ \\
\hline RPD & $\mathrm{t}=-0.11$ & $\mathrm{t}=0.56$ & $t=-0.49$ \\
\hline TFT & $\mathrm{t}=0.06$ & $\mathrm{t}=0.51$ & $\mathrm{t}=-0.54$ \\
\hline $\mathrm{RP}$ & $\mathrm{t}=0.13$ & $\mathrm{t}=-1.11$ & $\mathrm{t}=-2.75 *$ \\
\hline RRP & $\mathrm{t}=-0.91$ & $\mathrm{t}=-1.12$ & $\mathrm{t}=-1.96$ \\
\hline \multicolumn{4}{|l|}{ Auxiliary } \\
\hline FPRT & $\mathrm{t}=-1.08$ & $\mathrm{t}=0.21$ & $\mathrm{t}=-1.79$ \\
\hline RPD & $\mathrm{t}=-0.86$ & $\mathrm{t}=0.07$ & $\mathrm{t}=-2.48 *$ \\
\hline TFT & $\mathrm{t}=-0.47$ & $\mathrm{t}=1.47$ & $\mathrm{t}=-1.50$ \\
\hline $\mathrm{RP}$ & $t=-0.19$ & $\mathrm{t}=-0.29$ & $\mathrm{t}=-2.61 *$ \\
\hline RRP & $\mathrm{t}=0.83$ & $\mathrm{t}=1.11$ & $\mathrm{t}=-0.21$ \\
\hline
\end{tabular}

Table 9.10b: T-values for the disambiguating region.

\begin{tabular}{lllll}
\hline Condition & $(11 \mathrm{a})$ & $(11 \mathrm{~b})$ & $(12 \mathrm{a})$ & $(12 \mathrm{~b})$ \\
\hline Accuracy & $0.75(.02)$ & $0.73(.02)$ & $0.73(.02)$ & $0.69(.03)$ \\
\hline
\end{tabular}

Table 9.11: Comprehension accuracy, SE in brackets. 
Figure 9.1a: Example (5a), Gender and Noun Type Match. Bold line: nonconflicting binding.

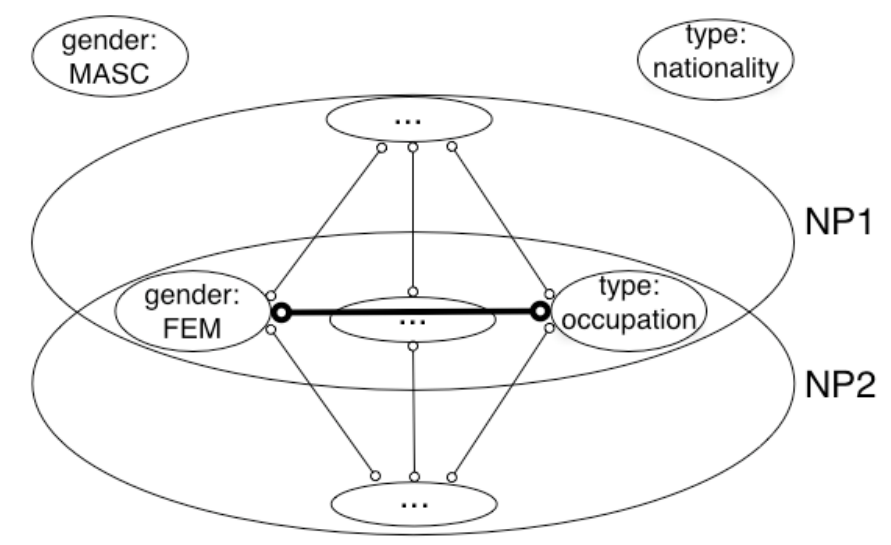

Figure 9.1b: Example (5b), Gender Mismatch. Bold dashed lines: conflicting bindings.

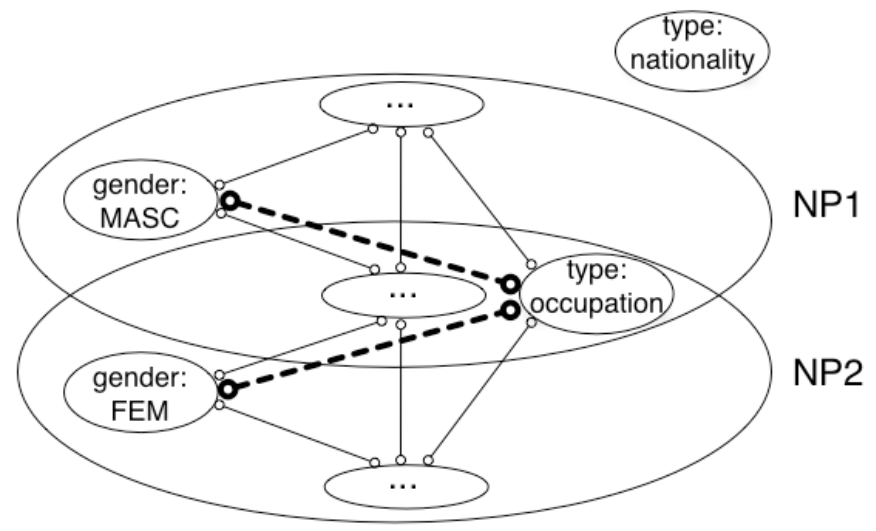


Figure 9.1c: Example (5c), Noun Type Mismatch. Bold dashed lines: conflicting bindings.

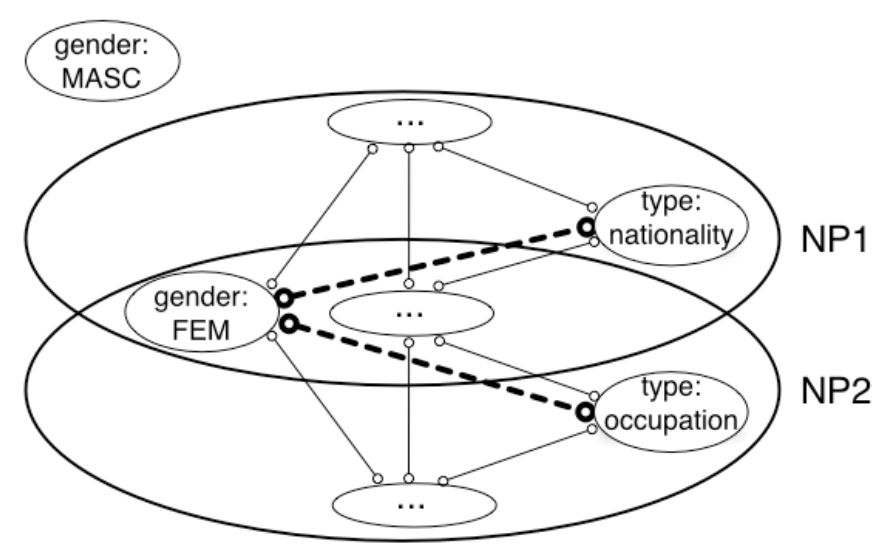

Figure 9.1d: Example (5d), Gender and Noun Type Mismatch. Bold lines: nonconflicting bindings.

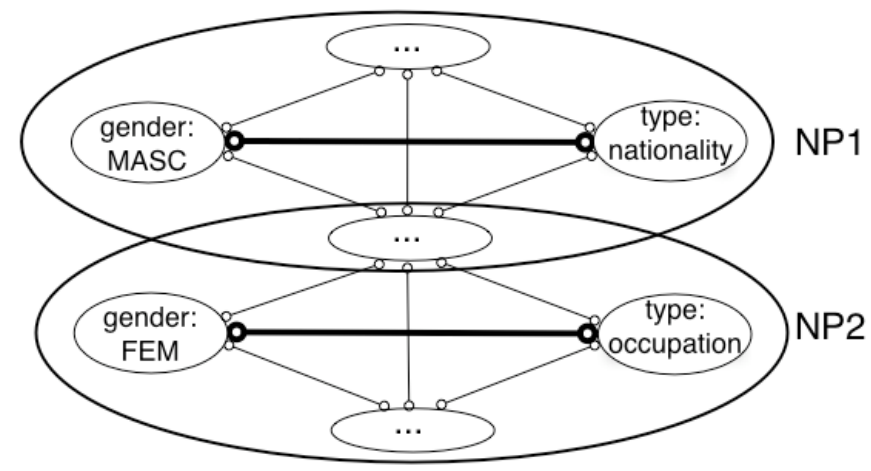

